\title{
Revisiting Uses and Gratification Theory: A Study on Visitors to Annah Rais Homestay
}

\author{
MUS CHAIRIL SAMANI \\ CATOHRINNER JOYCE GURI \\ Universiti Malaysia Sarawak
}

\begin{abstract}
Uses and gratification theory has always been discussed within the functional paradigm where the media serve a specific purpose for any given audience. The perspective assumes that people know even before using the media why they are using it. It is argued in this article that the actual purpose of using mass media is never determined beforehand. Audience is made aware of the purpose after accidentally finding something of interest while using the traditional mass media. Serendity of information occurs after using the mass media. Thus, functionality is assumed rather than verified while using the various mass media. With the advent of the Internet, people shift through the various websites to obtain information relating to a specific purpose. To deduce functionality, a study was conducted on the uses and gratification of websites on homestays. A survey was carried out with 100 actual visitors to Annah Rais Homestays, Sarawak using a specially built questionnaire to collect data relating to perceive and actual uses, and perceive and actual gratification of information obtained from websites of three homestays' service provider. The findings of the study conclusively found that the actual use of information after visiting a homestay is higher than the perceived use before visiting it. The actual gratification of information after visiting is higher than the perceived gratification before visiting it. Thus, the findings confirm the functionality of websites that could not have been proven in the various studies on traditional mass media.
\end{abstract}

Keywords: Uses and gratification, audience, Internet, websites, new media.

\section{INTRODUCTION}

Uses and gratification theory has generated a lot of research ever since Elihu Katz proposed it in 1959. The theory continues to generate new research as advancement in communication technologies facilitate new mode of interaction. As a theory that is grounded in functionalism, it has yet to provide supporting evidence that the traditional mass media caters to the needs of its audiences. Media such as newspapers, television and radio, the need for such services is discovered after people use it. The needs are not present before using it, except to gain entertainment.

With the advent of the Internet, people will usually surf the various websites such as news portals, blogs, and social media with a clear and distinct need. The need for information can be clearly illustrated when tourists look for suitable sites to visit. They will surf the various tourism related websites to obtain information on places of interest. The collated information is perceived to be of use to the visitor at the stage of surfing the Internet. The gratification related to the information obtained is also perceived to the visitor. It is after the visitor has toured the site will he or she be able to verify whether the information is of actual use and, thus obtained actual gratification. 
To test the notion of perceived and actual in the uses and gratification of websites, websites developed by proprietors of homestays at Annah Rais Village was chosen. These websites were chosen because proprietors of homestays at Annah Rais offer ethnic tourism packages that have been garnered visitors locally and internationally. As an ethnic tourism destination, Annah Rais Longhouse homestays highlight the important of environmental constructs, namely, cultural heritage attractions and natural resources as a niche in promoting rural tourism destination (Chin, Lo, Songan \& Nair, 2014, p. 40).

Three Annah Rais homestays' operators have advertised their services on the Internet. They understood the potential, ability and opportunities to connect with the world via the Internet. On this note, Abang Hashim $(2000$, p. 1) concurred that "Information is easily stored, manipulated, processed and delivered to the user on demand in as fast, accurate and responsive manner" over the Internet.

The internet has been celebrated by many for flattening all of the traditional structures around media ownership; bringing about economic transformation; allowing just anyone to be a media producer; and having huge significance in terms of democratic dialogue and political actions. On the face of it, the internet seems to offer almost utopian possibilities... (Devereux, 2014, p. 263).

In other words, the Internet revolution is making a big difference on ethnic tourism. Homestays operators are able to advertise their services to a wider audience, both locally and internationally. Previously, these operators will have to use the services provided by local and international mass media. The services provided by the mass media are not expensive and constraint according to demographics of the audience. With the Internet, these websites are continuously available at no extra cost, except for the monthly hosting and initial setup fees.

Review done on studies using the uses and gratification approach indicates that previous researcher did not differentiate between perceived and actual uses, and perceived and actual gratification of information obtained. This research investigates whether there is a different between perceived and actual uses, and perceived and actual gratification, if one is surfing information on the Internet to gather related materials about a tourism site.

The research objectives are: (1.) To investigate the perceived and actual uses that visitors to the homestays obtained while seeking information from the websites of homestays' operators, and (2) To evaluate the perceived and actual gratifications that visitors to the homestays obtained after they have visit or stayed at the homestays.

\section{LITERATURE REVIEW}

Uses and gratification theory has generated a lot of research interest among scholars. In his seminal work, The Effects of Mass Communication, Joseph Klapper (1960) reviewed decades of research on mass communication to conclude that first, the mass media appeared to have less power than the average citizen; second, that media effects are of a minor nature; and third, that the actual process of media effects is far more complex and a function of many factors. Klapper's conclusions were not dismissive of all media effects. Rather, they were directed toward effects of an indirect, long term, and complex nature, which could be based on a 
combination of psychological and social factors. The work marked a departure from hypodermic effect assumptions used during World War II propaganda research. Uses and gratifications emerged as an alternative perspective that could study and understand media effects as a result of more complex processes.

The theory is based on the idea that people use media for their own purposes. "In uses and gratification, audiences are seen as anything but passive. They decide which media they want to use and what effects they want the media to have" (Griffin, 2012, p. 358). Just as people want to get slim by exercising, uses and gratification theory assumes that people know why they are using the mass media, which is to fulfill or meet their particular needs. Griffin $(2012$, p. 359) stressed that "the deliberate choices people make in using media are presumably based on the gratifications they seek from those media." In other words, any content brought by media, like television will be perceived differently by different people on the type of needs that will be fulfilled.

Griffin (2012, p. 360) added that "the notion that media compete for attention and time is only an initial step in understanding the choices people eventually make." Thus, people will not recognize choice of media use until the need that motivates the behavior is fulfilled.

The theory also states that media are affecting people differently. Therefore, we will notice that users will react and perceive differently with the same media content. Griffin (2012, p. 360) stated that "one of the core concepts of uses and gratitification is that the same media messages does not necessarily affect everyone the same." Audience is a group of people who have different minds and ideas. Thus, the theory posed two questions "what do the people used the media for" and "why do they do it".

Studies have been done, among others, to investigate how social networking sites such as Facebook (see Karimi et al., 2014) are so enticing to the users. Another area of study looks at the gratification obtained from using computers among secondary school children (Abang Hashim, 2000).

Most of the studies done using the theory have focused on obtained gratifications (Karimi et al., 2014, p. 54). The focus is expected since the various studies look at the gratification obtained after exposure to the mass media. These studies assumed that the mass media served a function to the audience.

Olivine (2006, p. 20) support this notion when he says that, "in sum, the traditional approach of using gratification obtained in the study of motives in the adoption and use of media put much emphasis on the user's perspective and paid less attention on the attributes of the medium." If attributes of a medium are neglected, researchers will assume functions that are actually not present. The conducted study at Annah Rais Homestays took into consideration the attributes of the Internet.

Yuan (2011, p. 11) reviewed previous studies and concluded that there is essentially no difference between traditional and Internet in terms of the uses and gratifications that audiences seek. He came to the conclusion because Internet is still considered a form of mass media. In terms of forms and functions, the Internet is similar with traditional media that contains information and visual. 
Thus, Slot and Frissen (2007), opposed to the idea that there is no different between Internet and traditional mass media. They argued that users are in control of what they see on the Internet. Traditional media like television, newspaper and radio, the control is still in the hand of the respective producers who are also known as gatekeeper. On this note Slot and Frissen (2007, p. 201) argued that:

Web 2.0 services exploit connections between users, as these connections provide manifold opportunities for users to innovate. Not only are users actively consuming content, users also take on distribution roles in peer-topeer (P2P) file sharing networks, and content creation roles in the case of user-generated content.

In other words, people are consumer of media and actively controlling it. This is reflective of the actual formulation of uses and gratification theory that encourages diversification in the use of media. "Uses and gratifications theory has changed and matured in response to the development of new technologies, and what applies to traditional media does not necessarily apply to new media" (Yuan, 2011, p.11). Ballard (2011, p. 5) supported this by stating that, "... scholars who believed in the power of the audience to select and filter messages ultimately challenged the reigning ideology of the time and contested the widely accepted powerful-effects perspective society held regarding media messages."

Kraut, Kiesler, Boneva, Cummings, Helgeson and Crawford (2002) pointed out that Internet has the power to facilitate or discourage people using it depending on how they use the media. "Whether the Internet will have positive or negative social impact, however, may depend upon the quality of people's online relationships and upon what people give up to spend time online" (Kraut et al., 2002, p. 4). In this study, the user can feel encouraged or discouraged to visit Annah Rais Longhouse after they visit the website.

According to Larose and Eastin (2004), numerous studies on uses and gratification have been done on the Internet. Email and chatroom are common modes of Internet usage. They explained that user use Internet by accessing search engines for the purpose of conventional information seeking and entertainment gratifications. This is just suitable with the study as the visitor use the website to seek for information, later to fulfill the ir needs. Sunanda Sangwan (2005, p. 4) define, "Information for knowledge and understanding is gained through surveillance or participant and leads to learning, better decision making and improved time management."

According to Musa, Azmi and Ismail (2016, p. 86-87) in their article on "Exploring the Uses and Gratifications Theory in the Use of Social Media among the students of Mass Communication in Nigeria," "...majority of the people use social media for interaction, killing time, entertainment, seeking and sharing of information, socialization, self-expression, education, surveillance and communication. Using media purposely for information enhances the credibility of the Media Information Utility Theory, which argues that people rely on media for information." Hence in this study, it is contended that most of the visitors are seeking the information to feed their needs, which is to experience the ethnic tourism at Annah Rais Homestays. 
Most of the earlier studies investigate user behavior especially in how they perceived and acted after using media. "When it comes to user behavior and motivation, the U\&G theory has been the most common approach, explaining "why" certain media behavior occurs" (Karimi, 2014, p. 55). This study does not differentiate between perceived and actual uses of information, nor perceived and actual gratification.

Larose and Eastin (2004, p. 359) explained that "collectively these studies upheld one of the model basic propositions (Palmgreen, Wenner \& Rasengren, 1985), that gratification sought explain individual media exposure." In brief, gratification seek is known as gratification sought (GS) because it occurs at the point when a user encounters the media. GS is different from gratification obtained, according to Larose and Eastin (2004). They revealed that gratification obtained (GO) or known as actual gratification or delayed gratification can be understood through outcomes. Here, the outcome can only be determined by experience and behavior. However, studies have not been done to measure a user's experience or behavior.

Thus, most studies on the uses and gratification theory did not compared before and after using a medium. The comparison will allow researchers to determine whether there are actual differences between perceived and actual gratification. This aspect was taken into consideration in this study. On this note, Anabel Quan-Haase (2012, p. 3), contends that "the study of gratification has primarily focused on those gratifications obtained after adoption." She stresses that in uses and gratification, motivating user is an important element and GS should be studied.

LaRose and Eastin (2004) again stated that gratification sought and gratification obtained is somehow related but not similar. They contended that GS reflects to outcomes that are wished for while GO is not necessarily the achieved outcome. "Comparing gratifications sought with those obtained reflects the outcomes achieved in the past but not necessarily the likelihood that they will be repeated in future media consumption" (LaRose \& Eastin, 2014, p. 361). The GS outcome will update the experiences and behavioral consequences. Normally, GS could be negative predictors of media behavior if the users did not achieve their goals and needs and positive predictors of media if the users achieve their needs. Their behavior can be seen through their feedback. Thus, GS and GO is different. Keppler (2014) in his study on "Facebook and the Church: Gratification Sought and Gratification Obtained" says that GS and GO are umbrellas under uses and gratification theory on why people seek certain media and how they act. Thus, there is vast difference between these two: GO and GS.

Ballard (2011, p. 8) also concurs that "this extension of the theory suggests that whatever gratifications users expect to receive from a media may be different than what they actually receive." In "Uses and Gratification in Twitter Usage", Ballard believed that gratification obtained is a better predictor of media use during gratification sought. Usually, once if the needs meet, the use will be repeated. Thus, this study differentiates between perceived and actual gratification of visitors to Annah Rais Homestays.

Uses and gratification theory state that the usage of media is guided by a user's motive. The major motives include but not necessarily limited to seek knowledge, information, relaxation, social interaction and diversion. While it is accepted that people use media for relaxation purposes, it is not clear when and how motives relating to seeking knowledge, information, social interaction and diversion occur. Does the motive appear before a user uses 
a medium or after using it? If the motive is there before the user uses it, then it can be argued that the medium serves a function. Most of the time, people do not have a clue other than relaxation to explain the time spent on using a medium. This is because mass media offer a variety of programme and content to fulfill the various segments of audience. Thus, the argument that people have clearly identifiable motives underlying uses and gratification theory is questionable.

With the advent of the Internet, people are beginning to use the various channels of information available on the information superhighway differently. They will have a clear set of motives before surfing the Internet. Thus, researchers can identify the various motives of using the Internet before a user is using it, which is not clearly identifiable with traditional mass media. Thus, this research seeks to compare the reasons before and after user surfs the Internet for information. The types of uses and gratification obtained before and after surfing the Internet can be quantified and measured. It is posited in this research that the uses and gratification of a medium can be categorized as perceived and actual use, and perceived and actual gratification respectively.

Perceived use is a user's state of mind that the information obtained is useful but will need to be verified. The usefulness of the information will have to be verified after a user has used it. To illustrate the perceived and actual uses of information, we can take the case of a tourist who plans to spend a night at an unfamiliar homestay site. The user will surf the websites of the homestay's operator. The purpose of surfing the website is to gather all the necessary information regarding the homestay. The user will have to decide whether the collated information available on the website is appropriate. This is perceived use. When the tourist visits and stays at the homestay, the information obtained from the website will be verified. This is actual use.

Perceived gratification is a user's state of mind that the information obtained satisfies specific motives. The level of satisfaction will have to be verified after a user has experienced it. As in the case of the tourist, the information provided on the website will indicate whether the homestay will provide appropriate gratification. This is perceived gratification. When the tourist visits and stays at the homestay, the information obtained from the website will be verified. This is actual gratification.

Users of websites usually have a preconceived idea about the types of information that they are looking for. The intent will guide them on the types of websites to be surfed. Thus, these websites are actually fulfilling a function and not merely assumed to be doing so as in the case of traditional mass media such as television, radio, newspapers or magazines. Surfers of websites will look for information that is relevant to their needs. This can be observed among tourists who are planning to visit a place of interest. They will surf websites that fulfill their needs, sometimes repeatedly, to obtain all the information relating to the place of interest. With the collated and obtained information from the various websites, tourists will be able to gauge the types of activities and gratifications obtained if they later choose to visit the place. They will know whether the place is appropriate with their taste, lifestyle and budget. 
Figure 1(a) and (b) displays the original and modified theoretical framework uses and gratification that were used in this study.

a)
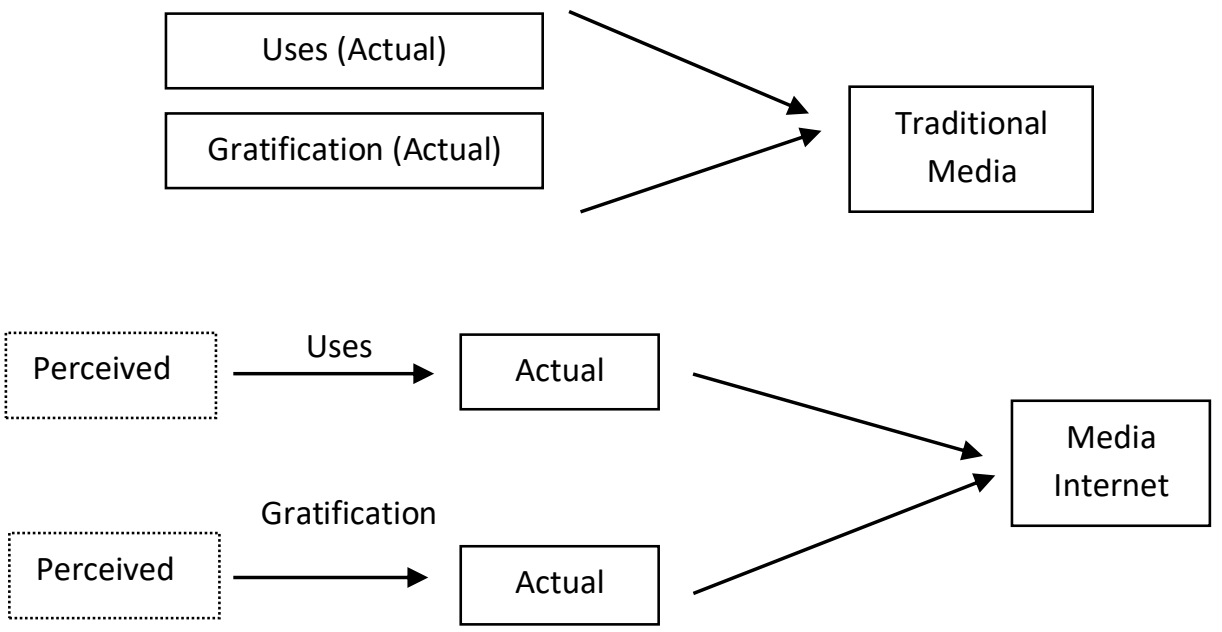

Figure 1: a) Original Uses and Gratification Theoretical Framework and

b) Modified Framework.

Several terms are defined specifically for this research. These terms are perceived use, actual use, perceived gratification and actual gratification.

\section{Perceived Use}

Philips, Francis, Webb and Bull (2010, p. 1125) define perceive as "to notice or become aware of something or to understand of think of something in a particular way." Uses derive from the root word, "use" which mean "to do something with a machine, a method, an object" (Philips et al., 2010, p. 1703). In simple explanation, perceived uses are to notice of something from an object or machine. In this study, perceived uses are defined as the use of a medium, including Internet to seek information on something of interest.

\section{Actual Use}

Actual is defined as "real, true, genuine, authentic, verified, attested, confirmed, definite, hard, plain, veritable, existing, existent, manifest, substantial, factual, de facto, bona fide, informal real live" (Hawker \& Waite, 2007, p. 13). Meanwhile the definition for uses is as mentioned above. Therefore, actual uses in this study are defined as the verified uses of a website after a visitor have visited a tourism site.

\section{Perceived Gratification}

According to Lee, Hoe, Chua and Ang (2009, p. 185), "Beyond ubiquitous content creation, context-aware, location-based information services are also now possible in mobile content sharing, allowing users to associate digital content with physical objects and locations in the 
real world, as well as receive content tailored to their specific needs." Perceived gratification is satisfaction that has yet to be verified because someone has yet to experience it personally. In this study, perceived gratification is defined as perceived satisfaction obtained by visitors that are looking for tourism related information from a particular website.

\section{Actual Gratification}

"Gratifications obtained refer to those gratifications that audience members actually experience through the use of a particular medium" (Karimi et al., 2014, p. 55). The gratification is obtained after someone experiences an actual situation or events. In this study, the actual gratification can be translated as their feedback. In this study, actual gratification is defined as the satisfaction, that visitors achieved after using the homestay websites and visit or stayed at the homestay. The hypotheses that were constructed and tested in this research were based on the theoretical framework.

\section{METHODOLOGY}

Survey was employed to gather data for this study. The method provides numerical description on attitude and opinion. The method allows for the largest number of participants to take part in the study. In addition, data obtained from survey enable a holistic understanding of uses and gratification. "A survey design provides a quantitative or numeric description of trends, attitudes, or opinions of a population by studying a sample of that population" (Creswell, 2014, p. 201).

The population of this study is the visitors who stayed at Annah Rais homestays. They consist of people who had obtained information about the homestays by surfing the website developed by operators of homestays at Annah Rais. The websites studied are Longhouse Adventure developed by the (late) Mr. Edward Gunui, Borneo Sarawak; Annah Rais Bidayuh Homestay operated by Madam Jenny, Madam Valarie and Madam Karum and Macheree's Homestay by Madam Macheree and Mr. Ringgin.

For the sampling, purposive sampling under non-probability sampling is preferred. Purposive sampling is known as "hand picked" or "exclusive" in the research. In other words, researcher already knows the type of people they want to choose for their research. In this study, the purposive sampling was used as the respondents are visitors that used the website to stay at Annah Rais. "In effect, they are selected with a specific purpose in mind, and that purpose reflects the particular qualities of the people or events chosen and their relevance to the topic of the investigation" (Denscombe, 1998, p. 15). This sampling allows the researcher to identify people that are relevant to the study. A total of 100 visitors who have stayed the Annah Rais Homestay including locals and foreigners that have surfed the homestays' website before arriving at Annah Rais was sampled.

As the actual population of those people staying at these homestays is not easily verifiable and fluctuate monthly, the researchers have decided to do a purposive sampling of individuals that visit and stay at these homestays from the months of June to October 2017. The consent of the homestays operators was obtained prior to the start of the study. The five months are considered as the best time to conduct the study because that there are many cultural and religious celebrations taking place. This includes the Gawai Dayak Celebration, Hari Raya Aidilfitri, National Day, Malaysia Day and Awal Muharram (Maal Hijrah). During these 
months, the prestigious World Harvest Festival and Rainforest World Music Festival are being held. The months between July and August are recognized as summer holidays in Europe. Thus, more locals and foreign tourists are expected to book and stay at these homestays. The months of November and January are considered wet seasons and thus often leads to low arrival of tourists whether local or international.

A self-administered questionnaire was developed to capture relating to the differences between perceived and actual in uses and gratification. The questionnaire was designed to capture the subjective nature of perception among people. People are assumed to have different perception on the uses of website as an information tool based on their previous exposure, interest and knowledge. Ahmad and Usop (2011, p. 135) mentioned that "a questionnaire is a predetermined set of questions designed to capture data from respondents." The questionnaire consists of "open-ended" and "close-ended" questions that were pretested and the alpha Cornbach reliability coefficient of over 0.9 was observed.

\section{DATA ANALYSIS}

A profile of respondents or visitors who consented to answering the questionnaire was developed. The descriptive profiling includes gender, religion, nationality, income and education as shown in table 1 . The collated fieldwork data indicates that the age of visitors staying at the homestays' range between 16 to 59 years old.

Out of 100 respondents in the study, table 1 shows that females (57 persons) made up the most number of visitors as compared to male (43 persons). In terms of religion, the majority of visitors to the homestay is Christian ( 49 persons) followed by Islam ( 29 persons), Buddha (18 persons), Hindu (1 person) and others (3 persons). As for nationalities, most of the visitors are Malaysian (73 persons) and the balance is non-Malaysian 27 (persons).

Table 1 also shows that people with a monthly salary of more than RM5001 (35 persons) made up the highest number of visitors to the homestays, while those with monthly salary between RM1001-RM2000 (16 persons), RM2001-RM3000 and RM3001-RM4000 (15 persons each), and RM4001-RM5000 (10 persons). A total of 8 people who are students did not state their montly income.

Table 1: Demographic Profile of Respondent.

\begin{tabular}{lll}
\hline Gender & Frequency & Percentage \\
Male & 43 & 43.0 \\
Female & 57 & 57.0 \\
& & \\
Religion & Frequency & Percentage \\
Islam & 29 & 29.0 \\
Christian & 49 & 49.0 \\
Buddha & 18 & 18.0 \\
Hindu & 1 & 1.0 \\
Others & 3 & 3.0 \\
& & \\
Nationality & Frequency & Percentage \\
Malaysian & 73 & 73.0 \\
Non-Malaysian & 27 & 27.0 \\
\hline
\end{tabular}




\begin{tabular}{lll}
\hline & Frequency & \\
Income & 8 & Percentage \\
None & 1 & 8.0 \\
Less than RM 1000 & 16 & 1.0 \\
RM 1001-RM 2000 & 15 & 16.0 \\
RM 2001-RM 3000 & 15 & 15.0 \\
RM 3001-RM 4000 & 10 & 15.0 \\
RM 4001-RM5000 & 35 & 10.0 \\
More than RM 5001 & & 35.0 \\
& Frequency & \\
Education & 16 & Percentage \\
Secondary School/PMR/SPM & 25 & 16.0 \\
STPM/Diploma & 43 & 25.0 \\
Bachelor Degree & 14 & 43.0 \\
Master & 2 & 14.0 \\
PHD & & 2.0 \\
\hline
\end{tabular}

$H_{1} \quad$ The actual uses of information is higher than the perceived uses of information on the homestays' website

The paired t-test was used with 0.05 degree of significance. The calculated mean for information after the visit is 8.73 and the mean before the visit is 7.29 . The calculated $t$ of 10.065 is significant at 0.000 (refer Table 2). The mean for information after visiting Annah Rais is higher than then perceived uses of information on the homestays website.

This indicates that the visitors to Annah Rais Longhouse homestay are actually satisfied on the uses of information after visiting the homestay as compared to before the visit. This is probably because before the visit, the information obtained is unverifiable knowledge that was obtained from the website. They are able to judge the quality of information obtained from the website after visiting the homestay.

Table 2: Paired sample t-test on uses and gratification on various information available on website before and after visiting homestays.

\begin{tabular}{lccrrc}
\hline \multicolumn{1}{c}{ Uses } & $\begin{array}{c}\text { Mean } \\
\text { Before Visit }\end{array}$ & $\begin{array}{c}\text { Mean } \\
\text { After Visit }\end{array}$ & \multicolumn{1}{c}{$\mathbf{t}$} & df & Sig (2 tailed) \\
\hline Information & 7.29 & 8.73 & 10.065 & 99 & .000 \\
Reservation & 7.55 & 8.80 & 9.355 & 99 & .000 \\
Packages & 7.56 & 8.77 & 7.698 & 99 & .000 \\
Transportation & 7.30 & 8.64 & 9.235 & 99 & .000 \\
Location & 3.62 & 8.52 & 40.426 & 99 & .000 \\
Tour and activities & 7.50 & 8.79 & 8.681 & 99 & .000 \\
$\quad$ & & & & & \\
$\quad$ Gratification & 7.49 & 8.83 & 8.671 & 99 & .000 \\
Homestay & 7.41 & 8.86 & 10.234 & 99 & .000 \\
Food & 7.53 & 8.92 & 10.258 & 99 & .000 \\
Environment & 7.46 & 9.13 & 12.666 & 99 & .000 \\
Homestay Operator & 7.52 & 9.14 & 12.097 & 99 & .000 \\
People of Annah Rais & 3.63 & 8.82 & 45.382 & 99 & .000 \\
Amenities & & & & & \\
\hline
\end{tabular}


$\mathrm{H}_{2}$ The actual uses of reservation is higher than the perceived uses of reservation on the homestays' website

The paired t-test was used with 0.05 degree of significance. The calculated mean for reservation after the visit is 8.80 and the mean before the visit is 7.55. The calculated t of 9.355 is significant at 0.000 (refer Table 2). The mean for reservation after visiting Annah Rais is higher than then perceived uses of reservation on the homestays website. It shows the visitors are satisfied with the reservation process after visited the Homestay. This is because the homestay operators provide and fulfill as per request in their reservation.

$H_{3} \quad$ The actual uses of package is higher than the perceived uses of package on the homestays' website

The paired t-test was used with 0.05 degree of significance. The calculated mean for package after the visit is 8.77 and the mean before the visit is 7.56 . The calculated $t$ of 7.698 is significant at 0.000 (refer Table 2). The mean for package after visiting Annah Rais is higher than then perceived uses of package on the homestays website. The visitors are satisfied on the uses of offered package after visiting the homestay as compared to before the visit. This is due to the different choices of packages for staying at the homestays that are made available is well reflected in the website. The packages include half day tour, 2 days and 1 night and 3 days and 2 nights. Thus, the visitors can also extend their stay up to a week.

$\mathrm{H}_{4} \quad$ The actual uses of transportation is higher than the perceived uses of transportation on the homestays' website

The paired t-test was used with 0.05 degree of significance. The calculated mean for transportation after the visit is 8.64 and the mean before the visit is 7.30 . The calculated t of 9.235 is significant at 0.000 (refer Table 2). The mean for transportation after visiting Annah Rais is higher than perceived uses of transportation on the homestays website. The visitors are satisfied with the uses the various mode of transportation that is available after visiting the Homestay. The mean before visit the homestay is lower than after could be due to visitors being skeptical of various mode of transportation available.

$\mathrm{H}_{5} \quad$ The actual uses of location is higher than the perceived uses of location on the homestays' website

The paired t-test was used with 0.05 degree of significance. The calculated mean for location after the visit is 8.52 and the mean before the visit is 3.62 . The calculated $t$ of 40.426 is significant at 0.000 (refer Table 2). The mean for location after visiting Annah Rais is higher than then perceived uses of location on the homestays website. This indicates that the visitors are satisfied with the uses of information on location after visiting the homestay. The before visit mean is much lower than after the visit. This could be due to the fact that visitors perceive the location of the homestay to be far. On the map, it is located about 60 kilometers from Kuching city. 
$H_{6} \quad$ The actual uses of tour and activities is higher than the perceived uses of tour and activities on the homestays' website

The paired t-test was used with 0.05 degree of significance. The calculated mean for tour and activities after the visit is 8.79 and the mean before the visit is 7.50 . The calculated $t$ of 8.681 is significant at 0.000 (refer Table 2). The mean for tour and activities after visiting Annah Rais is higher than perceived uses of tour and activities on the homestays website.

This indicates that the visitors are satisfied with the tour and activities after visiting the Annah Rais Longhouse Homestay. The reason for being satisfied is because they find the tourism site to be interesting, informative, relevant, adventurous, organized and authentic. After reading the information and following the guided tour and activities, they realized that the given information on tour and activities to be meaningful and the experience gained cannot be obtained at other places.

$\mathrm{H}_{7} \quad$ The actual gratification regarding homestay is higher than the perceived gratification regarding homestay

The paired t-test was used with 0.05 degree of significance. The calculated mean for homestay after the visit is 8.83 and the mean before the visit is 7.49. The calculated $t$ of 8.671 is significant at 0.000 (refer Table 2). The mean for homestay after staying at Annah Rais is higher than then perceived gratification of homestay on the homestays website. The visitors are satisfied with the Homestay after visiting it. This is could be because they found it to be clean, unique, beautiful, traditional and comfortable.

$\mathrm{H}_{8} \quad$ The actual gratification of local food is higher than the perceived gratification of local food

The paired t-test was used with 0.05 degree of significance. The calculated mean for local food after the visit is 8.86 and the mean before the visit is 7.41 . The calculated $t$ of 10.234 is significant at 0.000 (refer Table 2). The mean for local food after staying at Annah Rais is higher than then perceived gratification of local food on the homestays website.

The visitors seem to be satisfied with the local food provided after visiting the homestay. This is probably because they are able to taste the variety of food that are made available during their stay at the homestay.

$H_{9} \quad$ The actual gratification of environment is higher than the perceived gratification of environment

The paired t-test was used with 0.05 degree of significance. The calculated mean for environment after the visit is 8.92 and the mean before the visit is 7.53. The calculated $t$ of 10.258 is significant at 0.000 (refer Table 2). The mean for environment after staying at Annah Rais is higher than then perceived gratification of environment on the homestays website. Most of the visitors are satisfied with the environment at Annah Rais after visiting the place. They can verify that it is clean, green, and the view is breathtaking and pleasant. 
$\mathrm{H}_{10}$ The actual gratification regarding the homestay operator is higher than the perceived gratification regarding the homestay operator

The paired t-test was used with 0.05 degree of significance. The calculated mean for the homestay operator after the visit is 9.13 and the mean before the visit is 7.46 . The calculated $t$ of 12.666 is significant at 0.000 (refer Table 2). The mean regarding the homestay operator after staying at Annah Rais is higher than then perceived gratification regarding the homestay operator on the homestays website.

The visitors are satisfied with the homestay operator care and attitude after visiting the homestay. They were of the view that the homestay operator is friendly, helpful, warm and kind.

$H_{11}$ The actual gratification about the Annah Rais people is higher than the perceived gratification about the Annah Rais people

The paired t-test was used with 0.05 degree of significance. The calculated mean for the Annah Rais People after the visit is 9.14 and the mean before the visit is 7.52 . The calculated $t$ of 12.097 is significant at 0.000 (refer Table 2). The mean about the Annah Rais People after staying at Annah Rais is higher than then perceived gratification about the Annah Rais People on the homestays website. The visitors are pleased with the friendliness of Annah Rais people after visiting the homestay. The reason behind it could be that website merely gives information but meeting and knowing the people in person is a different experience. The visitors agree that the people at Annah Rais Village are warm, friendly and kind.

$\mathrm{H}_{12}$ The actual gratification on homestays' amenities is higher than the perceived gratification on homestays' amenities

The paired t-test was used with 0.05 degree of significance. The calculated mean for homestays amenities after the visit is 8.82 and the mean before the visit is 3.63 . The calculated t of 45.382 is significant at 0.000 (refer Table 2). The mean on homestays amenities after staying at Annah Rais is higher than then perceived gratification on homestays amenities on the homestays website.

The visitors are satisfied with the amenities available after visiting the homestay. The basic amenities available include electricity, water supply, road connection and signboard. The village has its own the tourist information centre that is known to be very helpful to new visitors. Every visitor is welcome with a glass of Annah Rais' well-known brand of rice wine.

\section{SUMMARY AND DISCUSSION}

The findings of this study support a new milestone in the communication field using uses and gratification theory. Most of the studies using this theory focus on gratification obtained or actual gratification after audience has exposed themselves to the respective media. "The concept of gratification is concerned with the types and degree of gratifications obtained from media exposure which fulfills the original needs initiating from the whole process of media use" (Roy, 2008, p. 78). Thus, for this study, the researcher not only investigated gratification after using a media but expand the theory to include perceived uses and gratification. In other words, the study covers aspect before audience uses a medium. In this research, the medium is 
the homestays website that audience surfes to obtain information relating to a tourism site. In other words, the media serves a specific function that has always been the underlying premise of this theory that audiences are active in the selection and exposure to the various media. This was assumed and was not substantiated with traditional media, such as television, radio or newspapers.

A medium is seen to serve a function if users determine what are the uses and gratification before exposure. With the Internet, people are generally aware of what they want to seek and obtain. These decisions are made and guide them while surfing the Internet. With traditional media, they only knew what they are seeking and looking for only after exposing themselves to the various medium. These media also decide on the content and programme to be offered which may or may not be related to the needs of the users.

On perceived gratifications, this finding is similar to the study done by Lee et al. (2009). They studied mobile devices that facilitate content sharing and retrieval of games. Studies on the Internet are most focus on social media use. "As social media networks continue to grow, evolve, and emerge in today's world, studies like this one become crucial to scholar's understanding of how people communicate in new, dynamic ways" (Ballard 2011, p. 46).

Further studies can be conducted at other homestays operators that have a present on the Internet by using the same instrument and method. Studies on homestays are important because owners of the private homes are opening their private space for visitors to stay. They are also promoting their culture, tradition and environment to the visitors.

\section{BIODATA}

Mus Chairi Samani is an Associate Professor in Communication at the Strategic Communication Programme, Faculty of Language and Communication, Universiti Malaysia Sarawak. Email: smchairil@unimas.my

Catohrinner Joyce Guri is a postgraduate student at the Faculty of Social Sciences and Humanities, Universiti Malaysia Sarawak. Email: catohrinnerjg@gmail.com 


\section{REFERENCES}

Abang Hashim, A. S. (2000). Uses and Gratifications: Perception, Perspectives and Patterns of Behavior of Students in Selected Secondary Schools in Urban Kuching with Regard to the Use of the Computer (Unpublished manuscript, Universiti Malaysia Sarawak, Kota Samarahan, Sarawak).

Ahmad, R., \& Usop, H. (2011). Conducting Research in Social Sciences, Humanities, Economics and Management Studies, A Practical Guide. Kuching: RS Group Publishing House.

Ballard, C. L. (2011). What's Happening" @Twitter: A Uses and Gratifications Approach (Unpublished master's thesis, University of Kentucky, Lexington).

Chin, C. H., Lo, M. C., Songan, P., \& Nair, V. (2014). Rural Tourism Destination Competitiveness: A Study on Annah Rais Longhouse Homestays, Sarawak. Procedia - Social and Behavioral Sciences, 144, 35-44. doi: 10.1016/j.sbspro.2014.07.271

Creswell, J. W. (2014). Research Design: Qualitative, Quantitative \& Mix Methods Approaches (4th ed.). Thousand Oaks: Sage.

Denscombe, M. (1998). The Good Research Guide for Small-Scale Social Research Projects. Buckingham: Open University Press.

Devereux, E. (2014) Understanding the Media. London: Sage.

Hawker, S., \& Waite, M. (2007). Concise Oxford Thesaurus (pp 13; 3th ed.). Oxford: Oxford University Press.

Keppler, C. C. (2014). Facebook and the Church: Gratifications Sought and Gratifications Obtaine (Unpublished master's thesis, The University of Akron, Akron).

Klapper, J.T. (1960). The Effects of Mass Communication. New York: Free Press.

Kraut, R., Kiesler, S., Boneva, B., Cummings, J., Helgeson, V., \& Crawford, A. (2002). Internet Paradox Revisited. Journal of Social Issues, 16(2), 49-74. doi: 10.1111/1540-4560.00248

LaRose, R., \& Eastin, M. S. (2004). A Social Cognitive Theory on Internet Uses and Gratifications: Toward a New Model of Media Attendance. Journal of Broadcasting \& Electronic Media, 48(3), 358-377. doi: 10.1207/s15506878jobem4803_2

Lee, C. S., Hoe, D. L. G., Chua, A. Y. K., \& Ang, R. P. (2009). Understanding Perceived Gratifications for Mobile Content Sharing and Retrieval in a Game-Based Environment. In J. Liu, J. Wu, Y. Y. Yao, \& T. Nishida (Eds.), Active Media Technology (pp. 183-194). Berlin: Springer.

Musa, A. S., Azmi, M. N. L., \& Ismail, N. S. (2016). Exploring the Uses and Gratificaitons Theory in the Use of Social Media among students of Mass Communication in Nigeria. Malaysian Journal of Distance Education, 17(2), 83-95. doi: 10.21315/mjde2015.17.2.6

Olivine, L. W. Y. (2006). The Roles of Gratification Opportunities, Gratifications-Obtained, and Demographics in Determining Usage Preference of Instant Messaging and E-mail among College Students (Unpublished master's thesis, The Chinese University of Hong Kong, Hong Kong).

Philips, P., Francis, B., Webb, S., \& Bull. V. (Eds.) (2010). Oxford Advanced Learner's Dictionary (8th ed.). Oxford: Oxford University Press.

Roy, S. K. (2008). Determining Uses and Gratifications for Indian Internet Users. CS-BIGS, 2(2), 78-91. Retrieved from https://goo.gl/U4mpkU 
Slot, M., \& Frissen, V. (2007). Users in The 'Golden' Age of The Information Society. Observatorio Journal, 3, 201-224.

Yuan, Y. (2011). A Survey Study on Uses and Gratification of Social Networking Sites in China (Unpublished master's thesis, University of Maryland, College Park). 